University of Nebraska - Lincoln

DigitalCommons@University of Nebraska - Lincoln

Faculty Publications from the Department of Electrical \& Computer Engineering, Department Electrical and Computer Engineering

4-15-1996

\title{
In situ and ex situ optical characterization of electro deposited magneto-optic materials
}

\author{
James N. Hilfiker \\ University of Nebraska-Lincoln \\ Darin W. Glenn \\ University of Nebraska-Lincoln \\ Scott W. Heckens \\ University of Nebraska-Lincoln \\ John A. Woollam \\ University of Nebraska-Lincoln, jwoollam1@unl.edu \\ Kurt W. Weirman \\ University of Nebraska-Lincoln
}

Follow this and additional works at: https://digitalcommons.unl.edu/electricalengineeringfacpub

Part of the Electrical and Computer Engineering Commons

Hilfiker, James N.; Glenn, Darin W.; Heckens, Scott W.; Woollam, John A.; and Weirman, Kurt W., "In situ and ex situ optical characterization of electro deposited magneto-optic materials" (1996). Faculty Publications from the Department of Electrical and Computer Engineering. 61.

https://digitalcommons.unl.edu/electricalengineeringfacpub/61

This Article is brought to you for free and open access by the Electrical \& Computer Engineering, Department of at DigitalCommons@University of Nebraska - Lincoln. It has been accepted for inclusion in Faculty Publications from the Department of Electrical and Computer Engineering by an authorized administrator of DigitalCommons@University of Nebraska - Lincoln. 


\title{
In situ and ex situ optical characterization of electro deposited magneto-optic materials
}

\author{
James N. Hilfiker, Darin W. Glenn, Scott Heckens, and John A. Woollam \\ Center for Microelectronic and Optical Materials Research, and Department of Electrical Engineering, \\ University of Nebraska, Lincoln, Nebraska 68588
}

Kurt W. Wierman

Department of Physics, University of Nebraska, Lincoln, Nebraska 68588

Electrodeposition is being investigated as a novel and low-cost method to prepare magneto-optic thin film and nanostructured materials. This deposition method allows precise control over thin-film properties and permits deposition of novel magnetic geometries. Multilayers and alloys can be deposited and controlled by adjusting deposition potentials and ion concentrations in the bath. Nickel/cobalt alloys have been electrodeposited from sulfamate, sulfate, and chloride solutions onto $\mathrm{Au}$ substrates. The optical properties were monitored in situ with a real-time spectroscopic ellipsometer measuring simultaneously at 44 wavelengths in the $410-750 \mathrm{~nm}$ spectral range. In situ measurements have the advantage of determining the material microstructural properties (thickness, density, and roughness) before the films are oxidized in the air ambient. Ex situ variable angle spectroscopic ellipsometry measurements were taken over the spectral range from 205 to $1000 \mathrm{~nm}$.

(C) 1996 American Institute of Physics. [S0021-8979(96)13308-2]

\section{INTRODUCTION}

Sputtered $\mathrm{Co} / \mathrm{Ni}$ and $\mathrm{Co} / \mathrm{Pt}$ nanometer thick multilayers can exhibit perpendicular magnetization and have previously been investigated as possible recording materials. ${ }^{1,2}$ Electrodeposition is investigated as a possible processing technique for similar magneto-optic materials. Alloys can be plated from an electrolyte containing ions of each of the elements to be plated. The ratio of ions in the electrolyte will have a direct effect on the thin-film alloy ratio, and the alloy ratio can be controlled by adjusting the electrolyte constituents. This control is desirable for many magneto-optic materials because of the effects of alloy ratios on Curie temperature, coercivity, optical response, and magneto-optic response. Control of the compensation temperature in $\mathrm{TbFeCo}$ is an example.

A full electromagnetic analysis of the multilayer boundary value problem, including dielectric tensor representation for all constituent layers, can provide information about observed optical and magneto-optical phenomena. ${ }^{3}$ Predictive modeling with this analysis method allows the optimization of magneto-optic disk performance. ${ }^{4}$ Accurate material properties (optical and magneto-optical constants) are necessary to simulate the optical and magneto-optical responses of a disk structure.

In order to accurately model the material thickness and microstructure, in situ spectroscopic ellipsometry measurements were taken during the electrodepositions. This allows the materials to be studied before oxidation, and thus the true material optical constants can be used for predictive modeling. The in situ measurements also allow diagnostics of time dependent growth effects. Optimization of the thin-film thicknesses and microstructure could be implemented by performing predictive modeling and then controlling the growth.

\section{EXPERIMENTAL PROCEDURE}

Electrodeposition of cobalt/nickel multilayers and alloys were carried out from the following electrolyte: $90 \mathrm{~g} / \ell$ nickel sulfamate, $30 \mathrm{~g} / \ell$ boric acid, and $X \mathrm{~g} / /$ of cobalt chloride (where $X$ is varied). Both potentiostatic and galvanostatic depositions were performed using a Princeton Applied Research (PAR) Model 173 potentiostat/galvanostat. A three electrode cell configuration was used in which the working electrode consisted of the substrate to be plated on, the counter electrode was a platinum foil, and the reference electrode was a saturated calomel electrode. A PAR Model 179 coulometer was used to monitor the charge passing through the sample during the deposition.

An electrochemical cell was designed with optical ports to allow ellipsometry measurements through the liquid. An in situ spectroscopic ellipsometer (J. A. Woollam Co., Inc.) was used to study the deposition processes. The in situ ellipsometer allowed 44 wavelengths to be measured simultaneously over the spectral range from 410 to $750 \mathrm{~nm}$ every 40 ms.

A series of cobalt/nickel multilayers and alloys were electrodeposited on optically thick gold films. The gold substrates were prepared by sputter deposition on silicon wafers. A chromium underlayer was first sputter deposited on the silicon substrate to act as an adhesion layer for the gold. $\mathrm{X}$-ray fluorescence measurements were taken on the series of samples to determine the thin-film cobalt-to-nickel alloy ratio.

In situ spectroscopic ellipsometry measurements were also taken on each of these films during deposition. This measurement tool allows the determination of the optical constants and thin-film thicknesses of the deposited layer and their time dependencies. The galvanostatic depositions were modeled with a constant growth rate material model. 

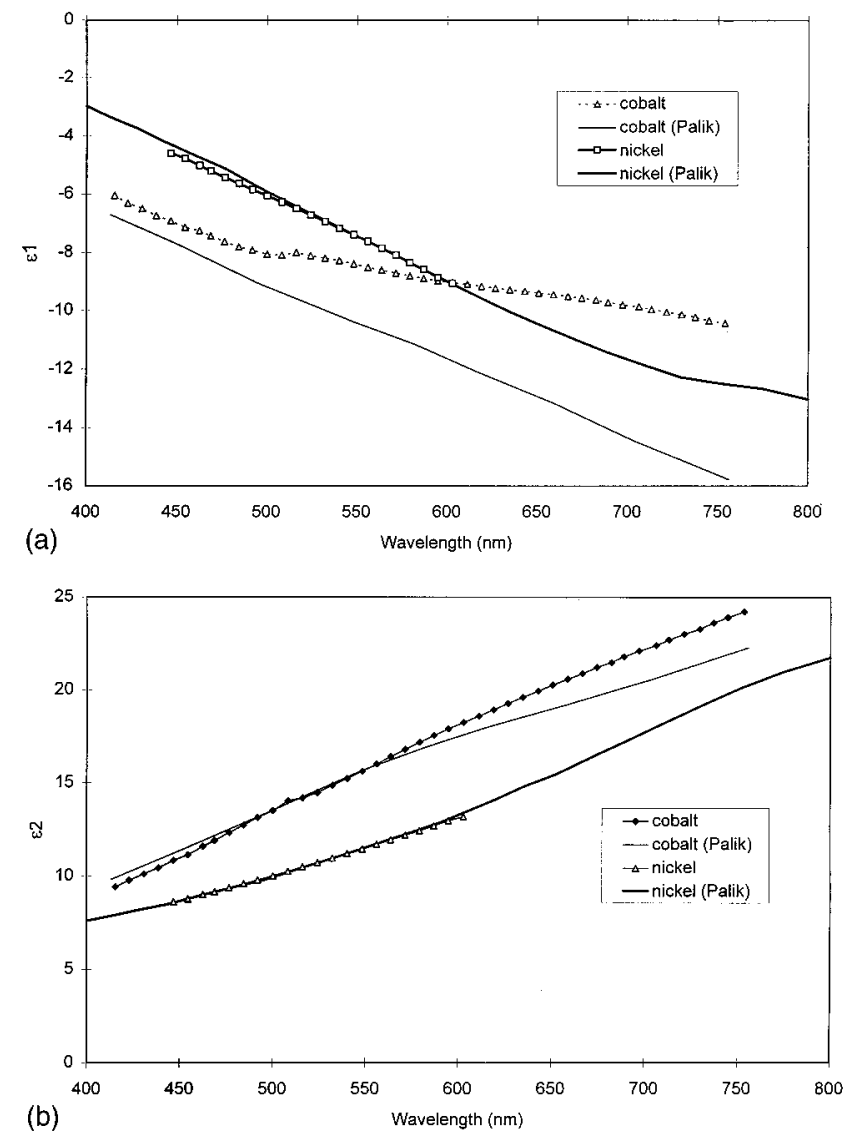

FIG. 1. (a) and (b): Comparison of optical constants determined from in situ spectroscopic ellipsometry and those from Palik. (Ref. 5).

\section{RESULTS}

The optical constants and growth rates were determined from in situ spectroscopic ellipsometry measurements taken during the electrodeposition process. The optical constants for cobalt and nickel were in reasonable agreement with values from the literature, as shown in Fig. 1, with the differences for cobalt probably due to surface roughness. ${ }^{5}$ A comparison between growth rates determined by in situ ellipsometry and coulometric calculations was also in good agreement. $^{6}$

Ex situ spectroscopic ellipsometry measurements on the optically thick cobalt/nickel alloys showed a basic trend of increasing $\epsilon_{1}$ and decreasing $\epsilon_{2}$ as the cobalt ion concentration, $X$, was increased. The pseudo-dielectric constants from in situ ellipsometry for one of the cobalt/nickel alloys are shown in Fig. 2. The film is optically thick after $5 \mathrm{~min}$ of deposition (time period shown), yet the dielectric constants continue to change with time. A roughness layer from effective medium theory was able to account for the changes during the early stages of film growth, but failed as the films continued to roughen. The in situ evidence that the films were roughening with increasing thickness was confirmed by ex situ interference microscope measurements. Alloys of cobalt/nickel deposited to the same final thickness were found to have increasing roughness with increasing cobalt concentration. Therefore, in order to predict the optical response of these electrodeposited materials, care must be
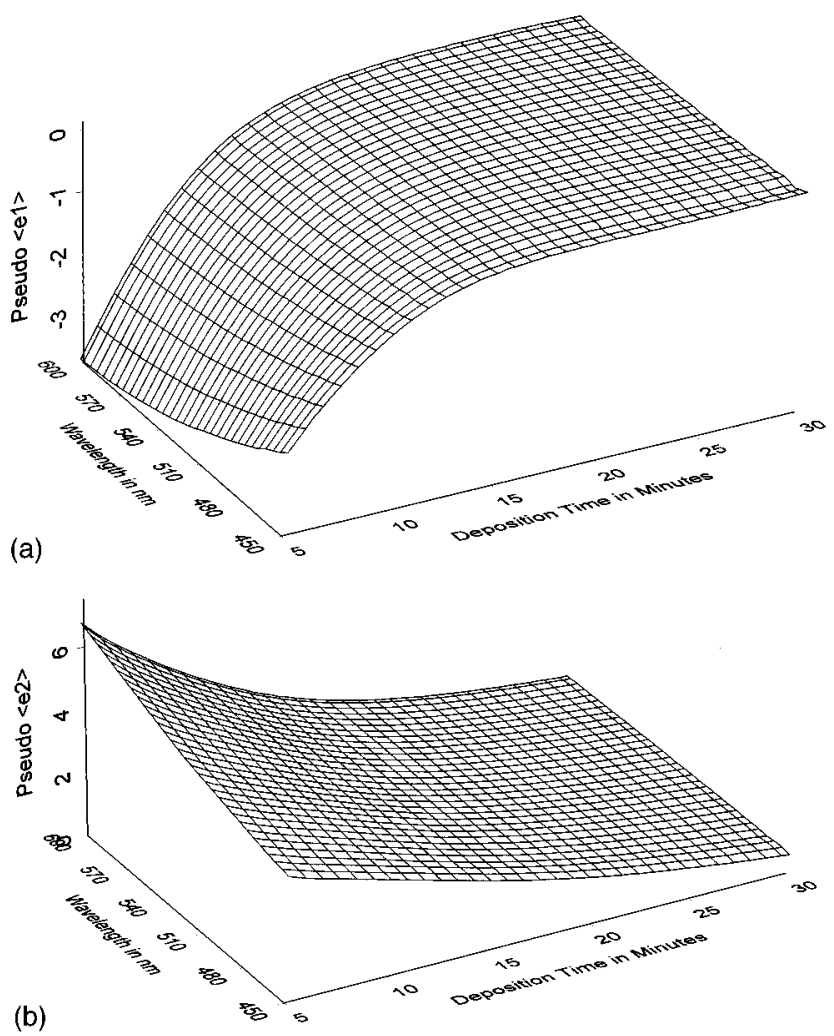

FIG. 2. (a) and (b): Pseudo-dielectric optical constants during the electrodeposition of a cobalt/nickel alloy thin film.

given to provide the correct optical model. Further calculations using a model without the inclusion of surface roughness would give incorrect results for magneto-optic constants. If the thickness is to be optimized, the theoretical calculations would have to consider the time dependent change in thin-film optical properties during the growth which would give rise to a different optical and magnetooptic response for different thin-film thicknesses.

Lashmore et al., have investigated electrodeposited copper/nickel multilayers for investigation of giant magne-

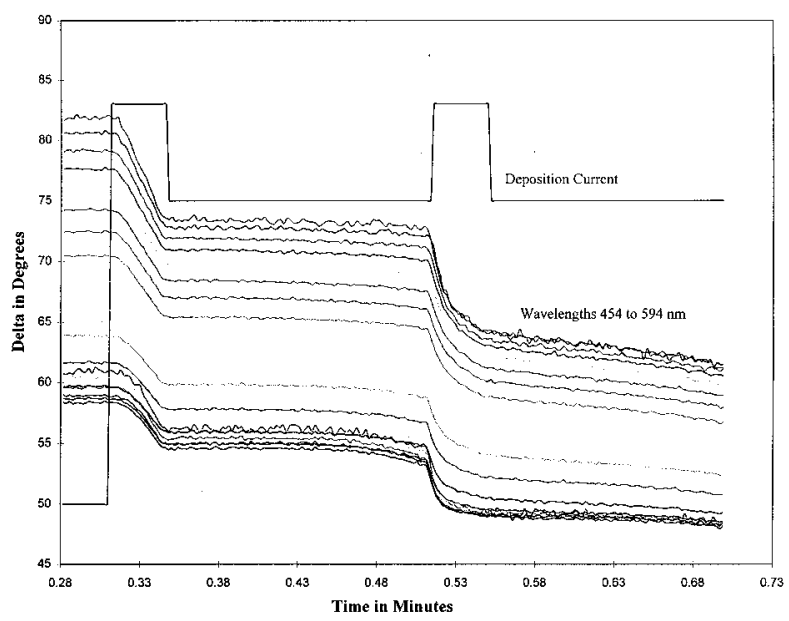

FIG. 3. In situ spectroscopic ellipsometry parameter (delta) during a copper/ nickel multilayer electrodeposition. 
toresistive effects. ${ }^{7}$ We have used in situ spectroscopic ellipsometry to study the electrodeposition of similar multilayers. For example, the ellipsometric delta parameter during a copper/nickel multilayer deposition is shown in Fig. 3. The multilayers are deposited from the same solution by pulsing to different currents (also shown in Fig. 3).

\section{CONCLUSION}

Electrodeposition is an interesting technique which allows the processing of magneto-optic materials. Both alloy and multilayer thin films have been formed with this technique. In situ spectroscopic ellipsometry allowed diagnostics of the electrodeposition process. The optical constants from ellipsometry are in good agreement with those from the literature, and will be needed to optimize any magneto-optic device structures.

\section{ACKNOWLEDGMENT}

Supported by the National Science Foundation, Grant No. NSF-OSR 9255225.

${ }^{1}$ Y. B. Zhang, P. He, J. A. Woollam, J. X. Shen, R. D. Kirby, and D. J. Sellmyer, J. Appl. Phys. 75, 6495 (1994).

${ }^{2}$ P. He, W. A. McGahan, J. A. Woollam, F. Sequeda, T. McDaniel, and H. Do, J. Appl. Phys. 69, 4021 (1991).

${ }^{3}$ J. N. Hilfiker, Y. B. Zhang, and J. A. Woollam, IEEE Trans. Magn MAG30, 4437 (1994).

${ }^{4}$ P. He, William A. McGahan, and J. A. Woollam, Proc. SPIE 1499, 401 (1991).

${ }^{5}$ Edward D. Palik, Handbook of Optical Constants of Solids (Academic, Orlando, 1985).

${ }^{6}$ J. N. Hilfiker, D. W. Thompson, J. S. Hale, and J. A. Woollam, Thin Solid Films 270, 73 (1996).

${ }^{7}$ D. S. Lashmore and M. P. Dariel, J. Electrochem. Soc. 135, 1218 (1988). 